\title{
Patient-reported Satisfaction with Current Clinical Management of Systemic Lupus Erythematosus in Kazakhstan
}

\author{
Yeldos Khamitov ${ }^{1}$, Zaituna Khismetova ${ }^{1}$, Maiya Goremykina ${ }^{1}$, Sandro Vento ${ }^{2}$, Arkadiy Kotlyar $^{3}$, Natalya Glushkova ${ }^{4 *}$ \\ ${ }^{1}$ Department of Public Health and Evidence Based Medicine, Semey Medical University, Semey, Kazakhstan; ${ }^{2}$ Faculty of \\ Medicine, University of Puthisastra, Phnom Penh, Cambodia; ${ }^{3}$ Integrative Medicine Clinic, Rishon LeZion, Israel; ${ }^{4}$ Department \\ of Personalized Medicine, Semey Medical University, Semey, Kazakhstan
}

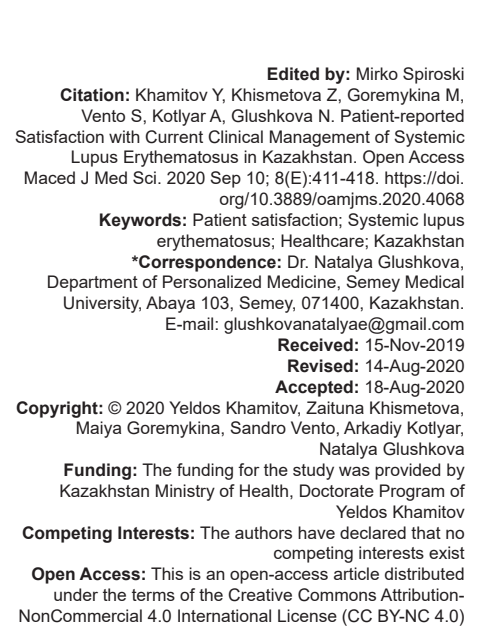

\begin{abstract}
BACKGROUND: Over the past decades, patient satisfaction has been increasingly recognized as a powerful tool to measure the quality of health-care services.

AIM: This study evaluated the satisfaction of systemic lupus erythematosus (SLE) patients with current clinica management in Semey, East Kazakhstan, and explored the factors associated with dissatisfaction.

METHODS: All adult SLE patients registered at health-care facilities of Semey were enrolled in a cross-sectiona study.

RESULTS: Out of 67 patients, 66 were females and their mean age was 39 years. Symptoms associated with the musculoskeletal system were the most commonly reported $(95.5 \%)$, followed by fatigue $(88.1 \%)$ and neurological symptoms $(53.7 \%)$. None of the patients were very satisfied or satisfied with current clinical management and the overall rate of patient dissatisfaction was $83.6 \%$. Education $(p=0.04)$, monthly income $(p=0.01)$, SLE disease activity index score $(p=0.031)$, therapy with biologic agents $(p=0.029)$, immunosuppressants $(p=0.01)$, and corticosteroids $(p=0.01)$ were predictors of patient dissatisfaction in multiple logistic regression analysis.

CONCLUSION: This real-world study is the first effort to understand the experience of SLE patients within the healthcare system of Kazakhstan and the results may facilitate doctor-patient discussions on the initiatives that need to be

taken to improve the quality of the medical services provided.
\end{abstract}

\section{Introduction}

At present, patient satisfaction is extensively used to evaluate the quality of health-care services, as it is considered an important indicator of health-care system functioning. Patient satisfaction has multiple influences on patient compliance and retention, treatment outcomes, and medical malpractice claims [1]. In general, patients are likely to be satisfied with the quality of services if these are provided in a timely, efficient, and patient-oriented manner. The nature of disease might also affect satisfaction with the quality of care as patients suffering from chronic progressive disorders tend to be less satisfied [2].

Systemic lupus erythematosus (SLE) is characterized by gradual worsening of general symptoms with periodic remissions and relapses under treatment. There is no cure for this disease and available therapies can only postpone disability and fatality [3]. SLE is treated with a variety of drugs, including nonsteroidal anti-inflammatory drugs, corticosteroids (CSs), antimalarials, immunosuppressants (ISs), and disease-modifying antirheumatic drugs (DMARDs). Nowadays, a "treat to target" strategy is applied, signifying that remission or low disease activity is a primary therapeutic target [4].

Being SLE one of the "great masqueraders," it is often diagnosed after multiple visits of the patients to health-care facilities with many tests performed [5]. Moreover, adherence to treatment and drug compliance appear to be poor, as only a quarter of all SLE patients take $80 \%$ of prescribed medications or more within a period of 2 years [6]. Being poor compliance associated with worse clinical outcomes, patients are less likely to be satisfied with the quality of care. To improve treatment adherence, medical professionals try to minimize adverse effects while improving treatment efficacy and need to balance a range of factors such as number of drugs prescribed and dose intervals [7], [8].

A number of international studies reported about satisfaction of SLE with the care provided and complexity of treatment regimen and the balance between treatment efficacy and adverse effects were among the most important determinants [9]. Meanwhile, according to Jolly and co-authors, 
greater social support and coping were associated with higher satisfaction in SLE patients [10]. Such physical factors as tenderness of joints and pain on movement, fatigue, anxiety, malar rash, and photosensitivity were associated with higher dissatisfaction of SLE patients [11]. Notwithstanding that patient satisfaction has been increasingly studied by Kazakhstani care providers over the past years, no data about satisfaction with the quality of care of SLE patients exist [12], [13]. Thus, our study evaluated the satisfaction of SLE patients in Semey, East Kazakhstan.

\section{Methods and Patients}

This was a cross-sectional study, conducted from May 2018 to June 2019, which enrolled all adult SLE patients registered at the health-care facilities of Semey. The Regional Health Authority has established a Rheumatology Clinical Registry that collects compulsory information on all patients with confirmed rheumatologic disorders during the course of routine clinical practice. From the electronic database, we extracted information on all SLE patients aged 18 years and older, contacted them by phone, and invited them to participate in the study. The only exclusion criteria were a psychiatric disease-causing cognitive impairment and inability to take part in the study (in the investigator's opinion) and patient's refusal to take part in the study. All 67 invited patients accepted to participate.

All patients were interviewed during their regular visits to the rheumatologist following them, without the presence of any eventual accompanying person. Before a patient was interviewed, his/her rheumatologist filled in a record form containing information related to the SLE status (including time course, presence of disability, organ involvement, Systemic Lupus International Collaborating Clinics American College of Rheumatology (SLICC/ACR) index, SLE disease activity index (SLEDAI), and type of treatment prescribed). To quantify the damage that had occurred since SLE onset, the SLICC/ACR index was applied [14], while to assess SLE, the SLEDAI was used [15].

All patients were asked to complete a paper questionnaire consisting of a demographic part and a patient satisfaction part. The demographic questions were related to patient's age, gender, ethnicity, education, and personal income (defined on the basis of the median salary as of 2017 according to the report of the National Committee on Statistics) [16]. To describe the degree of satisfaction with current clinical management and status monitoring, patients were asked to self-evaluate the extent of their satisfaction on the basis of a six-point Likert scale (very satisfied, satisfied, somewhat satisfied, somewhat dissatisfied, dissatisfied, and very dissatisfied) [17]. Subsequently, for the purposes of logistic regression analysis, we dichotomized the degree of satisfaction using the following cutoff points: Satisfied (very satisfied, satisfied, or somewhat satisfied) and dissatisfied (very dissatisfied, dissatisfied, or somewhat dissatisfied).

\section{Ethical Aspects}

Approval of the Ethics Committee of Semey Medical University was obtained before the start of the study. All SLE patients gave written informed consent to participate after receiving detailed information on the study aim and procedures. Confidentiality of data was ensured.

\section{Statistical analysis}

The data analysis comprised three stages and was performed using IBM SPSS Statistics 20 software. Before application of any statistical test, the Shapiro-Wilk test was used to define normal data distribution. The $95 \%$ confidence interval of proportion was calculated using Wald method.

At the first stage of data analysis, the basic descriptive statistics were conducted on sociodemographic and clinical characteristics of SLE patients. While continuous variables were evaluated with the help of frequencies and means, categorical variables were evaluated based on the number and percentage of patients in each category. No missing data had to be removed from the list of variables, as both rheumatologists and SLE patients answered all questions. At the second stage of data analysis, descriptive tests of various sociodemographic and clinical factors associated with patient satisfaction were carried out.

At the third stage, we performed multiple logistic regression analysis for dichotomous outcomes to identify various risk factors associated with patient dissatisfaction. For this, we combined three grades of dissatisfaction (very dissatisfied, dissatisfied, or somewhat dissatisfied) into one (dissatisfied). Patient age was dichotomized into $<40$ years and $\geq 40$ years. Education level was dichotomized into the higher or secondary vocational and secondary or unfinished secondary. Monthly income was dichotomized into $\leq 83,000$ Tenge and more than 83,000 Tenge (median monthly salary in the Republic of Kazakhstan as of 2017). SLICC/ACR score was categorized as no damage (score $=0$ ) and presence of any damage (score $\geq 1$ ), while SLEDAI score was dichotomized as a score $<4$ and equal to 4 and higher.

For all data analyses conducted, $p<0.05$ were considered statistically significant. 


\section{Results}

Overall, this study comprised 67 SLE patients, of whom $66(98.5 \%)$ were females. Most patients $(86.6 \%)$ were of Kazakh origin, which corresponds with ethnic structure of Kazakhstani population [18]. The mean age was 39 years (SD \pm 12$)$. About half of all patients $(49.3 \%)$ had attained higher or secondary vocational education. Most people $(79.1 \%)$ had a monthly income of $<83,000$ Tenge and the majority of patients $(82.1 \%)$ had been followed-up for 1 year or longer. The sociodemographic data of the patient population studied are summarized in Table 1.

The most commonly reported symptoms were associated with the musculoskeletal system (95.5\%) followed by fatigue (88.1\%). Neurological symptoms were the third most frequently reported (53.7\%), while gastrointestinal symptoms were reported by $49.3 \%$ of patients. Symptoms of depression or anxiety were present only in $13.4 \%$ of patients and seizures were reported by one patient $(1.5 \%)$ (Table 2$)$. The majority of patients $(97.0 \%)$ were treated with CSs while $10.4 \%$ received ISs and only one patient $(1.5 \%)$ was on DMARDs therapy. All patients on CS therapy (methylprednisolone) and ISs (mycophenolate mofetil) received the drugs for free according to the Provision

Table 1: Sociodemographic characteristics of the study participants $(n=67)$

\begin{tabular}{|c|c|c|}
\hline Characteristic & $\mathrm{n}$ & $\%$ \\
\hline \multicolumn{3}{|l|}{ Gender } \\
\hline Female & 66 & 98.5 \\
\hline Male & 1 & 1.5 \\
\hline \multicolumn{3}{|l|}{ Ethnic origin } \\
\hline Kazakhs & 58 & 86.6 \\
\hline Russians & 9 & 13.4 \\
\hline \multicolumn{3}{|l|}{ Age, mean \pm standard deviation } \\
\hline \multicolumn{3}{|l|}{$39 \pm 12$ years } \\
\hline \multicolumn{3}{|l|}{ Education } \\
\hline Unfinished secondary & 9 & 13.4 \\
\hline Secondary & 25 & 37.3 \\
\hline Secondary vocational & 18 & $26.9 \%$ \\
\hline Higher & 15 & 22.4 \\
\hline \multicolumn{3}{|l|}{ Monthly income $^{a}$} \\
\hline$\leq 83,000$ Tenge ${ }^{*}$ & 53 & 79.1 \\
\hline More than 83,000 Tenge * & 14 & 20.9 \\
\hline \multicolumn{3}{|l|}{ Duration of follow-up } \\
\hline$<1$ year & 12 & 17.9 \\
\hline More than 1 year & 55 & 82.1 \\
\hline \multicolumn{3}{|c|}{$\begin{array}{l}\text { Age at presentation of first clinical symptoms, mean } \pm \text { standard deviation } \\
30 \pm 11 \text { years }\end{array}$} \\
\hline
\end{tabular}

Table 2: Clinical findings in SLE patients $(n=67)$

\begin{tabular}{lll}
\hline Symptoms and signs & $\mathrm{f}$ & $\%$ \\
\hline Musculoskeletal symptoms & 64 & 95.5 \\
Fatigue & 59 & 88.1 \\
Neurological symptoms & 36 & 53.7 \\
Gastrointestinal symptoms & 33 & 49.3 \\
Cardiovascular symptoms & 30 & 44.8 \\
Mucocutaneous symptoms & 29 & 43.3 \\
Raynaud's phenomenon & 28 & 41.8 \\
Fever & 26 & 38.8 \\
Skin rash & 19 & 28.4 \\
Respiratory symptoms & 15 & 22.4 \\
Morning stiffness & 13 & 19.4 \\
Nodules & 12 & 17.9 \\
Ulcers & 11 & 16.4 \\
Infection & 11 & 16.4 \\
Depression/anxiety & 9 & 13.4 \\
Genitourinary symptoms & 7 & 10.4 \\
Significant infection & 5 & 7.5 \\
Thrombosis & 3 & 4.5 \\
Seizures & 1 & 1.5 \\
\hline SLE: Systemic lupus erythematosus. & &
\end{tabular}

of a guaranteed amount of free medical care in Kazakhstan [19].

None of the patients were satisfied or very satisfied with their current clinical management and status monitoring. Only 11 patients (16.4\%) were somewhat satisfied with the quality of care and the rest were dissatisfied to a certain extent. Level of education and monthly income was significantly related to patient satisfaction, and as far as clinical factors are concerned, nearly all except for immunosuppressive therapy were associated with patient satisfaction (Tables 3 and 4). Multiple logistic regression analysis showed that education $(p=0.04)$, monthly income $(p=0.01)$, SLEDAI score $(p=0.031)$, DMARDs therapy $(p=0.029)$, ISs therapy $(p=0.01)$, and CSs therapy $(p=0.01)$ predicted patient dissatisfaction with current clinical management and status monitoring (Table 5).

\section{Discussion}

The main finding of our study is the low rate of patient satisfaction (16.4\%). This finding is very similar to that of Chinese colleagues, who reported on $32.38 \%$ satisfaction rate of SLE patients, which was influenced by the defects in patients' education on health-care system [20]. Clinical manifestations of SLE and quality of life also significantly correlated with patient satisfaction [21]. Prescription of certain types of medications like CSs plays a role in reduced satisfaction of SLE patients [22]. Besides, lack of social support and low-quality medical services can undermine the trust of SLE patients in care provided [23]. There are several possible explanations for low patient satisfaction that needs to be considered in detail.

In the study, we found that variables level of education (OR $=1.251 ; 95 \% \mathrm{Cl}: 1.005-2.453)$, monthly income (OR $=2.41 ; 95 \% \mathrm{Cl}: 1.543-6.419)$, SLEDAI score $(\mathrm{OR}=1.511 ; 95 \% \mathrm{Cl}: 1.218-3.241)$, DMARDs therapy $(\mathrm{OR}=1.619 ; 95 \% \mathrm{Cl}: 1.013-1.986)$, ISs therapy $(\mathrm{OR}=1.321 ; 95 \% \mathrm{Cl}: 1.014-3.494)$, and CSs therapy $(\mathrm{OR}=2.163 ; 95 \% \mathrm{Cl}: 1.300-3.045)$ were significantly associated with patient dissatisfaction.

A recent systematic review [24] investigated different factors associated with patient satisfaction and identified quality indicators of health-care services as the most powerful determinants. According to this review, there are nine determinants of satisfaction with existing health-care services, some of which are of greater importance than others. In particular, both continuity of care and outcome of care have significantly positive effects on overall patient satisfaction. These could be considered from two perspectives: Provider-related and patient-related. While patients tend to assess the impact of care in terms of their daily life activities, doctors tend to rely on clinical indicators. 
Table 3: Patient satisfaction in relation to sociodemographic characteristics $(n=67)$

\begin{tabular}{|c|c|c|c|c|c|c|c|c|c|c|c|c|c|c|c|c|c|c|c|c|}
\hline \multirow[t]{3}{*}{ Characteristic } & \multicolumn{18}{|c|}{ Overall satisfaction } & \multicolumn{2}{|c|}{ Test of difference } \\
\hline & \multicolumn{3}{|c|}{ Very dissatisfied } & \multicolumn{3}{|c|}{ Dissatisfied } & \multicolumn{3}{|c|}{ Somewhat dissatisfied } & \multicolumn{3}{|c|}{ Somewhat satisfied } & \multicolumn{3}{|c|}{ Satisfied } & \multicolumn{3}{|c|}{ Very satisfied } & \multirow[t]{2}{*}{$\chi^{2}$} & \multirow[t]{2}{*}{$\mathrm{p}$-value } \\
\hline & $\mathrm{n}$ & $\%$ & $95 \% \mathrm{Cl}$ & $\mathrm{n}$ & $\%$ & $95 \% \mathrm{Cl}$ & $\mathrm{n}$ & $\%$ & $95 \% \mathrm{Cl}$ & $\mathrm{n}$ & $\%$ & $95 \% \mathrm{Cl}$ & $n$ & $\%$ & $95 \% \mathrm{Cl}$ & $n$ & $\%$ & $95 \% \mathrm{Cl}$ & & \\
\hline \multicolumn{21}{|l|}{ Age, years } \\
\hline$>20$ & 0 & 0 & - & 2 & 8.70 & $\begin{array}{l}2.42- \\
26.8\end{array}$ & 1 & 9.09 & $\begin{array}{l}1.62- \\
37.73\end{array}$ & 1 & 9.09 & $\begin{array}{l}1.62- \\
37.73\end{array}$ & 0 & 0 & - & 0 & 0 & - & \multirow[t]{6}{*}{12.595} & \multirow[t]{6}{*}{0.634} \\
\hline $20-29$ & 7 & 31.82 & $16.36-52.68$ & 3 & 13.04 & $\begin{array}{l}4.54- \\
32.12\end{array}$ & 0 & 0.00 & - & 2 & 18.18 & $\begin{array}{l}5.14- \\
47.70\end{array}$ & 0 & 0 & - & 0 & 0 & - & & \\
\hline $30-39$ & 4 & 18.18 & $7.31-38.51$ & 8 & 34.78 & $\begin{array}{l}18.81- \\
55.11\end{array}$ & 3 & 27.27 & $\begin{array}{l}9.74- \\
56.56\end{array}$ & 3 & 27.27 & $\begin{array}{l}9.74- \\
56.56\end{array}$ & 0 & 0 & - & 0 & 0 & - & & \\
\hline $40-49$ & 7 & 31.82 & $16.36-52.68$ & 5 & 21.74 & $\begin{array}{l}9.66- \\
41.90\end{array}$ & 5 & 45.45 & $\begin{array}{l}21.27- \\
71.99\end{array}$ & 2 & 18.18 & $\begin{array}{l}5.14- \\
47.70\end{array}$ & 0 & 0 & - & 0 & 0 & - & & \\
\hline $50-59$ & 3 & 13.64 & $4.75-33.34$ & 5 & 21.74 & $\begin{array}{l}9.66- \\
41.90\end{array}$ & 2 & 18.18 & $\begin{array}{l}5.14- \\
47.70\end{array}$ & 3 & 27.27 & $\begin{array}{l}9.74- \\
56.56\end{array}$ & 0 & 0 & - & 0 & 0 & - & & \\
\hline $\begin{array}{c}>60 \\
\text { Gender }\end{array}$ & 1 & \multicolumn{17}{|c|}{ Gender } & & \\
\hline Female & 22 & 100.00 & - & 22 & 95.65 & $\begin{array}{l}79.01- \\
99.23\end{array}$ & 11 & 100.00 & - & 11 & 100.00 & - & 0 & 0 & - & 0 & 0 & - & \multirow[t]{3}{*}{1.942} & \multirow[t]{2}{*}{0.585} \\
\hline Male & 0 & 0.00 & - & 1 & 4.35 & $\begin{array}{l}0.77- \\
20.99\end{array}$ & 0 & 0.00 & - & 0 & 0.00 & - & 0 & 0 & - & 0 & 0 & - & & \\
\hline \multicolumn{20}{|l|}{ Education } & \\
\hline $\begin{array}{l}\text { Unfinished } \\
\text { secondary }\end{array}$ & 9 & 40.91 & $23.26-61.27$ & 0 & 0.00 & - & 0 & 0.00 & - & 0 & 0.00 & - & 0 & 0 & - & 0 & 0 & - & \multirow[t]{4}{*}{47.639} & \multirow[t]{4}{*}{0.000} \\
\hline Secondary & 3 & 13.64 & $4.75-33.34$ & 17 & 73.91 & $\begin{array}{l}53.53- \\
87.45\end{array}$ & 5 & 45.45 & $\begin{array}{l}21.27- \\
71.99\end{array}$ & 0 & 0.00 & - & 0 & 0 & - & 0 & 0 & - & & \\
\hline $\begin{array}{l}\text { Secondary } \\
\text { vocational }\end{array}$ & 6 & 27.27 & $13.15-48.15$ & 1 & 4.35 & $\begin{array}{l}0.77- \\
20.99\end{array}$ & 3 & 27.27 & $\begin{array}{l}9.74- \\
56.56\end{array}$ & 8 & 72.73 & $\begin{array}{l}43.44- \\
90.26\end{array}$ & 0 & 0 & - & 0 & 0 & - & & \\
\hline Higher & 4 & 18.18 & $7.31-38.51$ & 5 & 21.74 & $\begin{array}{l}9.66- \\
41.90\end{array}$ & 3 & 27.27 & $\begin{array}{l}9.74- \\
56.56\end{array}$ & 3 & 27.27 & $\begin{array}{l}9.74- \\
56.56\end{array}$ & 0 & 0 & - & 0 & 0 & - & & \\
\hline \multicolumn{21}{|l|}{ Monthly income } \\
\hline $\begin{array}{l}\leq 83,000 \\
\mathrm{KZT}^{*}\end{array}$ & 22 & 100.00 & - & 19 & 82.61 & $\begin{array}{l}62.86- \\
93.02\end{array}$ & 9 & 81.82 & $\begin{array}{l}52.30- \\
94.86\end{array}$ & 3 & 27.27 & $\begin{array}{l}9.74- \\
56.56\end{array}$ & 0 & 0 & - & 0 & 0 & - & \multirow[t]{2}{*}{23.910} & \multirow[t]{2}{*}{0.000} \\
\hline $\begin{array}{l}\text { More than } \\
83,000 \\
\text { KZT }^{*}\end{array}$ & 0 & 0.00 & - & 4 & 17.39 & $\begin{array}{l}6.98- \\
37.14\end{array}$ & 2 & 18.18 & $\begin{array}{l}5.14- \\
47.70\end{array}$ & 8 & 72.73 & $\begin{array}{l}43.44- \\
90.26\end{array}$ & 0 & 0 & - & 0 & 0 & - & & \\
\hline
\end{tabular}

Table 4: Patient satisfaction in relation to clinical characteristics $(n=67)$

\begin{tabular}{|c|c|c|c|c|c|c|c|c|c|c|c|c|c|c|c|c|c|c|c|c|}
\hline \multirow[t]{3}{*}{ Characteristic } & \multicolumn{18}{|c|}{ Overall satisfaction } & \multicolumn{2}{|c|}{ Test of difference } \\
\hline & \multicolumn{3}{|c|}{ Very dissatisfied } & \multicolumn{3}{|c|}{ Dissatisfied } & \multicolumn{3}{|c|}{ Somewhat dissatisfied } & \multicolumn{3}{|c|}{ Somewhat satisfied } & \multicolumn{3}{|c|}{ Satisfied } & \multicolumn{3}{|c|}{ Very satisfied } & \multirow[t]{2}{*}{$x^{2}$} & \multirow[t]{2}{*}{$p$-value } \\
\hline & $\mathrm{n}$ & $\%$ & $95 \% \mathrm{Cl}$ & $\mathrm{n}$ & $\%$ & $95 \% \mathrm{Cl}$ & $\mathrm{n}$ & $\%$ & $95 \% \mathrm{Cl}$ & $\mathrm{n}$ & $\%$ & $95 \% \mathrm{Cl}$ & $\mathrm{n}$ & $\%$ & $\begin{array}{l}95 \% \\
\mathrm{Cl}\end{array}$ & $\mathrm{n}$ & $\%$ & $\begin{array}{l}95 \% \\
\mathrm{Cl}\end{array}$ & & \\
\hline \multicolumn{21}{|l|}{ Duration of follow-up } \\
\hline$\leq 1$ year & 2 & 9.1 & $\begin{array}{l}2.53- \\
27.81\end{array}$ & 1 & 4.3 & $\begin{array}{l}0.80- \\
20.99\end{array}$ & 7 & 63.6 & $\begin{array}{l}35.38- \\
84.84\end{array}$ & 2 & 18.2 & $5.14-4.77$ & 0 & 0 & - & 0 & 0 & - & 19.685 & 0.000 \\
\hline$>1$ year & 20 & 90.9 & $\begin{array}{l}72.19- \\
97.47\end{array}$ & 22 & 95.7 & $\begin{array}{l}79.01- \\
99.23\end{array}$ & 4 & 36.4 & $\begin{array}{l}15.16- \\
64.62\end{array}$ & 9 & 81.8 & $\begin{array}{l}52.30- \\
94.86\end{array}$ & 0 & 0 & - & 0 & 0 & - & & \\
\hline \multicolumn{21}{|l|}{ Presence of disability } \\
\hline Yes & 10 & 45.5 & $\begin{array}{l}26.92- \\
65.34\end{array}$ & 10 & 43.5 & $\begin{array}{l}25.64- \\
63.19\end{array}$ & 2 & 18.2 & $\begin{array}{l}5.14- \\
4.77\end{array}$ & 10 & 90.9 & $\begin{array}{l}62.27- \\
98.38\end{array}$ & 0 & 0 & - & 0 & 0 & - & 12.282 & 0.006 \\
\hline No & 12 & 54.5 & $\begin{array}{l}34.66- \\
73.08\end{array}$ & 13 & 56.5 & $\begin{array}{l}36.81- \\
74.36\end{array}$ & 9 & 81.8 & $\begin{array}{l}52.30- \\
94.86\end{array}$ & 1 & 9.1 & $\begin{array}{l}1.62- \\
37.73\end{array}$ & 0 & 0 & - & 0 & 0 & - & & \\
\hline \multicolumn{21}{|l|}{ SLICC/ACR score } \\
\hline$=0$ & 0 & 0 & - & 0 & 0 & - & 0 & 0 & - & 0 & 0 & - & 0 & 0 & - & 0 & 0 & - & - & - \\
\hline$\geq 1$ & 22 & 100.0 & - & 23 & 100.0 & - & 11 & 100.0 & - & 11 & 100.0 & - & 0 & 0 & - & 0 & 0 & - & & \\
\hline \multicolumn{21}{|l|}{ SLEDAI score } \\
\hline$<4$ & 5 & 22.7 & $\begin{array}{l}10.12- \\
43.44\end{array}$ & 6 & 26.1 & $\begin{array}{l}12.55- \\
46.47\end{array}$ & 2 & 18.2 & $\begin{array}{l}5.14- \\
4.77\end{array}$ & 9 & 81.8 & $\begin{array}{l}52.30- \\
94.86\end{array}$ & 0 & 0 & - & 0 & 0 & - & 14.532 & 0.002 \\
\hline$\geq 4$ & 17 & 77.3 & $\begin{array}{l}56.56- \\
89.88\end{array}$ & 17 & 73.9 & $\begin{array}{l}53.53- \\
87.45\end{array}$ & 9 & 81.8 & $\begin{array}{l}52.30- \\
94.86\end{array}$ & 2 & 18.2 & $5.14-4.77$ & 0 & 0 & - & 0 & 0 & - & & \\
\hline \multicolumn{21}{|l|}{ DMARDs therapy } \\
\hline Yes & 0 & 0.0 & - & 0 & 0.0 & - & 0 & 0.0 & - & 2 & 18.2 & $5.14-4.77$ & 0 & 0 & - & 0 & 0 & - & 10.495 & 0.015 \\
\hline No & 22 & 100.0 & - & 23 & 100.0 & - & 11 & 100.0 & - & 9 & 81.8 & $\begin{array}{l}52.30- \\
94.86\end{array}$ & 0 & 0 & - & 0 & 0 & - & & \\
\hline \multicolumn{21}{|l|}{ ISs therapy } \\
\hline Yes & 18 & 81.8 & $\begin{array}{l}61.49- \\
92.69\end{array}$ & 21 & 91.3 & $\begin{array}{l}7.32- \\
97.58\end{array}$ & 11 & 100.0 & - & 10 & 90.9 & $\begin{array}{l}62.27- \\
98.38\end{array}$ & 0 & 0 & - & 0 & 0 & - & 2.782 & 0.426 \\
\hline No & 4 & 18.2 & $\begin{array}{l}7.31- \\
38.51\end{array}$ & 2 & 8.7 & $\begin{array}{l}2.40- \\
2.68\end{array}$ & 0 & 0.0 & - & 1 & 9.1 & $\begin{array}{l}1.62- \\
37.73\end{array}$ & 0 & 0 & - & 0 & 0 & - & & \\
\hline \multicolumn{21}{|l|}{ CSs therapy } \\
\hline Yes & 1 & 4.5 & $0.80-2.18$ & 2 & 8.7 & $\begin{array}{l}2.40- \\
2.68\end{array}$ & 0 & 0.0 & - & 8 & 72.7 & $\begin{array}{l}43.44- \\
90.26\end{array}$ & 0 & 0 & - & 0 & 0 & - & 30.837 & 0.000 \\
\hline No & 21 & 95.5 & $\begin{array}{l}78.20- \\
99.19\end{array}$ & 21 & 91.3 & $\begin{array}{l}7.32- \\
97.58\end{array}$ & 11 & 100.0 & - & 3 & 27.3 & $\begin{array}{l}9.74- \\
56.56\end{array}$ & 0 & 0 & - & 0 & 0 & - & & \\
\hline
\end{tabular}
OR: Odds ratio, $\mathrm{Cl}$ : Confidence
modifying antirheumatic drugs

In our study, almost all patients had musculoskeletal symptoms - one of the most influential predictors of poor ability to perform daily life activities. Arthritis and myositis are two common manifestations of SLE and are both associated with significant pain and physical disability [25]. Although typical SLE affects small joints, larger joints may be also involved, making the daily routine tasks of the patients difficult [26]. Arthralgia and myalgia - other common manifestations of SLE contribute to decreased physical functioning and provoke psychological distress [27]. Besides, fatigue is one of the main findings in SLE and it was observed in almost $90 \%$ of our study population. Fatigue is not necessarily related to disease activity but is rather correlated with 
Table 5: Logistic regression analysis of predictors (risk factors) for patient dissatisfaction with current clinical management and status monitoring $(n=67)$

\begin{tabular}{|c|c|c|}
\hline \multirow[t]{3}{*}{ Risk factors } & \multicolumn{2}{|l|}{ Outcome variable } \\
\hline & \multicolumn{2}{|l|}{ Patient dissatisfaction } \\
\hline & OR $(95 \% \mathrm{Cl})$ & $\mathrm{p}$-value \\
\hline \multicolumn{3}{|l|}{ Education } \\
\hline Secondary vocational and higher & Reference & - \\
\hline Secondary and unfinished secondary & $1.251(1.005-2.453)$ & 0.040 \\
\hline \multicolumn{3}{|l|}{ Age } \\
\hline$<40$ years & Reference & - \\
\hline$\geq 40$ years & $0.831(0.215-4.589)$ & 0.831 \\
\hline \multicolumn{3}{|l|}{ Gender } \\
\hline Female & Reference & - \\
\hline Male & $1.213(0.637-3.322)$ & 0.944 \\
\hline \multicolumn{3}{|l|}{ Monthly income } \\
\hline$\leq 83,000 \mathrm{KZT}^{*}$ & $2.41(1.543-6.419)$ & 0.010 \\
\hline More than $83,000 \mathrm{KZT}^{*}$ & Reference & - \\
\hline \multicolumn{3}{|l|}{ Duration of follow-up } \\
\hline$\leq 1$ year & Reference & - \\
\hline$>1$ year & $0.94(0.116-1.118)$ & 0.999 \\
\hline \multicolumn{3}{|l|}{ SLICC/ACR score } \\
\hline$=0$ & Reference & - \\
\hline$\geq 1$ & $1.256(0.426-1.215)$ & 0.742 \\
\hline \multicolumn{3}{|l|}{ SLEDAI score } \\
\hline$<4$ & Reference & - \\
\hline$\geq 4$ & $1.511(1.218-3.241)$ & 0.031 \\
\hline \multicolumn{3}{|l|}{ DMARDs therapy } \\
\hline Yes & Reference & - \\
\hline No & $1.619(1.013-1.986)$ & 0.029 \\
\hline \multicolumn{3}{|l|}{ ISs therapy } \\
\hline Yes & Reference & - \\
\hline No & $1.321(1.014-3.494)$ & 0.001 \\
\hline \multicolumn{3}{|l|}{ CSs therapy } \\
\hline Yes & Reference & - \\
\hline No & $2.163(1.300-3.045)$ & 0.001 \\
\hline
\end{tabular}

other factors such as the presence of mental distress and pain syndrome [28]. Since musculoskeletal symptoms and fatigue prevailed in our patients, these could be one of the possible explanations for the high dissatisfaction rate. Possibly a high fatigue prevalence in Kazakhstani SLE patients could be also associated with geographical features of the country that characterized by Vitamin $D$ deficiency [29].

In addition, neurological symptoms and presence of depression or anxiety are correlated with decreased psychological functioning and also affect patient satisfaction. Seizures and cerebrovascular disease, such as permanent or transient cerebral ischemic episodes, are considered the most common neurological manifestations of SLE [30]. Although seizures were observed in only one patient in our study, more than half of all patients presented with some neurological symptoms. Depression is one of the commonest psychiatric manifestations of SLE, with prevalence rates ranging from 17 to $75 \%$ [31]. Despite the fact that in our study, only a few patients had symptoms of depression or anxiety, these numbers are likely to be underestimated as both depression and anxiety are stigmatized in Kazakhstan [32] and doctor who is not psychiatrists has little ability to recognize and properly manage them. Depression and anxiety may have also contributed to our patients' dissatisfaction.

Albeit there was a relatively small proportion of patients presenting with genitourinary symptoms (10.4\%), nephritis is a frequent complication of SLE and substantially contributes to lethality [33]. In general, chronic kidney disease tends to be underestimated by health-care providers in Kazakhstan. This situation is very similar to the one observed in the Russian Federation, which experiences acute insufficient staffing in nephrology services along with the insufficient provision of renal replacement therapy [34]. Thus, there is a need to introduce international clinical practice guidelines on diagnostic, therapeutic, and preventive approaches for SLE patients presenting with nephritis and to increase awareness among both medical professionals and patients on associated health risks.

Availability of health care, including effective and timely therapy, is another determinant of patient satisfaction and is inter-related with treatment outcomes [24]. DMARDs are a new approach to managing disease activity and Belimumab is the only biological agent currently registered in Kazakhstan for SLE treatment. In this study, only two patients were on Belimumab and both were somewhat satisfied with the current clinical management. Logistic regression analysis showed that non-provision of Belimumab is also a predictor of patient dissatisfaction $(p=0.029)$.

Since DMARDs therapy can reduce SLE activity and flares, its unavailability is associated with the increased use of other anti-SLE agents such as CSs and ISs. According to the recommendations of the European League Against Rheumatism, ISs should be considered in non-responsive SLE patients, or in those patients who require CSs above the doses recommended for chronic use [35]. Although CSc and ISs have many known side effects, they can effectively control SLE activity and in our study non-provision of CSs or ISs therapy was found to be a statistically significant risk factor for patients' dissatisfaction with current disease management $(p=0.001)$. This was also associated with SLE activity based on SLEDAI score, with a cutoff value of 4: Those patients who presented with active disease had a higher chance to be dissatisfied with current SLE management as compared to those who presented with inactive disease (SLEDAI score < 4).

In general, patient-related characteristics such as age, gender, level of education, monthly income, marital status, ethnicity, and length of follow-up are considered less powerful determinants of patient satisfaction [24]. Although in our study, we failed to establish associations between patient dissatisfaction and age, gender or duration of follow-up, level of education, and monthly income were found to be strong predictors of discontent. Such, patients with secondary or unfinished secondary education had higher odds $(\mathrm{OR}=1.25)$ of being dissatisfied with the quality of care provided as compared to patients with higher or secondary vocational education. This finding helps to conclude that the level of patient education has a direct relationship with patient satisfaction. In addition, patients with monthly income below the country's average had a 2.4 times higher chance of being dissatisfied with SLE management compared to their wealthier counterparts. 


\section{managers}

Implications for the practice of health-care

Since there is a lack of Kazakhstani studies on patient satisfaction with the quality of medical care, the results of this research could be useful for health-care managers as they enable a better understanding of the factors affecting the satisfaction of SLE patients and give insights on what needs to be done to improve it.

Kazakhstan Republic experienced rapid economic growth over the past decades of years and is now considered to be one of the emerging economies [36]. Being led by extensive oil production, the country's government took measures to equip the healthcare facilities with the latest diagnostic and treatment tools to enable adequate quality of health-care provided to the country population [12]. Furthermore, health-care managers strived to ensure that medical professionals meet requirements set by the Ministry of Health that dictates competences and qualifications of health-care providers. However, the issue of patient satisfaction is often overlooked by health-care managers in their attempt to upgrade the quality of health services [13].

Still, the degree of patient satisfaction could serve as one of the key performance indicators for healthcare services as it has a direct impact on the status of any health-care facility. In general, patient satisfaction signifies a facility's success on the basis of satisfactory patient feedback [37]. Moreover, it can be one of the key indicators for adjudicating health outcomes of individual patients. Good patient satisfaction is a preferred outcome of any medical care and is an important aspect of patient's health status [38]. As patient satisfaction is a valuable measurement of the quality of medical care, this research contributes to enhancement of the quality of health-care services provided to SLE patients in Kazakhstan.

\section{Strengths and limitations}

This study has several strengths and limitations. The major limitations come from its cross-sectional design and from the fact that it is being a single-city study. However, there are several strengths and the main one is that this is the first Kazakhstani study to report about the experiences of SLE patients within the local health-care system, which may facilitate doctorpatient discussions on what steps need to be taken to improve the quality of medical services provided.

\section{Conclusion}

The results of this study show the low satisfaction of SLE patients with medical services provided in Semey and identify the key determinants of patient dissatisfaction. The type of therapy provided along with SLE activity, level of education, and patient's monthly income appeared to be the key drivers of dissatisfaction. The management of patients with SLE as well with other chronic diseases in Kazakhstan remains provider-centered and little emphasis is placed on the recognition of patient's perceptions and views. Consideration of patients' views and experiences is essential if a program aiming to improve the quality of care of SLE is envisaged. In addition, the findings of our study may facilitate the start of a dialog with the health-care authorities on the current status of SLE management in Kazakhstan and may help to achieve better clinical outcomes in the future.

\section{Contributors}

All authors have contributed to manuscript writing and review and have approved the final version.

\section{Acknowledgments}

We would like to thank all the patients who participated in the study and the managerial staff of health-care facilities who made this study possible.

\section{References}

1. Berg JS, Dischler J, Wagner DJ, Raia JJ, Palmer-Shevlin N Medication compliance: A healthcare problem. Ann Pharmacother. 1993;27(9):S1-24.

PMid:8400462

2. Poulos GA, Brodell RT, Mostow EN. Improving quality and patient satisfaction in dermatology office practice. Arch Dermatol. 2008;144(2):263-5. https://doi.org/10.1001/ archdermatol.2007.58

PMid:18283191

3. Rivas-Larrauri F, Yamazaki-Nakashimada MA. Systemic lupus erythematosus: Is it one disease? Reumatol Clin. 2016;12(5):274-81. https://doi.org/10.1016/j.reuma.2016.01.005 PMid:26922326

4. Adinolfi A, Valentini E, Calabresi E, Tripoli A, Governato G, Zucchi D, et al. One year in review 2016: Systemic lupus erythematosus. Clin Exp Rheumatol. 2016;34(4):569-74. PMid:27463977

5. Sebastiani GD, Prevete I, Iuliano A, Minisola G. The importance of an early diagnosis in systemic lupus erythematosus. Isr Med Assoc J. 2016;18(3-4):212-5.

PMid:27228646

6. Marengo MF, Waimann CA, de Achaval S, Zhang H, GarciaGonzalez A, Richardson MN, et al. Measuring therapeutic adherence in systemic lupus erythematosus with electronic 
monitoring. Lupus. 2012;21(11):1158-65. https://doi. org/10.1177/0961203312447868

\section{PMid:22588588}

7. Barbosa CD, Balp MM, Kulich K, Germain N, Rofail D. A literature review to explore the link between treatment satisfaction and adherence, compliance, and persistence. Patient Prefer Adherence. 2012;6:39-48. https://doi.org/10.2147/ppa.s24752 PMid:22272068

8. De Achaval S, Suarez-Almazor ME. Treatment adherence to disease-modifying antirheumatic drugs in patients with rheumatoid arthritis and systemic lupus erythematosus. Int $\mathrm{J}$ Clin Rheumatol. 2010;5:313-26. https://doi.org/10.2217/ijr.10.15 PMid:20676388

9. Mathias SD, Berry P, Pascoe K, de Vries J, Askanase AD, Colwell $\mathrm{HH}$, et al. Treatment satisfaction in systemic lupus erythematosus: Development of a patient-reported outcome measure. J Clin Rheumatol. 2017;23(2):94-101. https://doi. org/10.1097/rhu.0000000000000495

PMid:28225511

10. Jolly M, Sethi B, O'Brien C, Sequeira W, Block JA, Toloza S, et al. Drivers of satisfaction with care for patients with lupus. ACR Open Rheumatol. 2019;1(10):649-56.

PMid:31872187

11. Mozaffarian N, Lobosco S, Lu P, Roughley A, Alperovich G Satisfaction with control of systemic lupus erythematosus and lupus nephritis: Physician and patient perspectives. Patient Prefer Adherence. 2016;10:2051-61. https://doi.org/10.2147/ppa.s111725 PMid:27784995

12. Dauletyarova M, Semenova Y, Kaylubaeva G, Manabaeva G, Khismetova Z, Akilzhanova Z, et al. Are women of East Kazakhstan satisfied with the quality of maternity care? Implementing the WHO tool to assess the quality of hospital services. Iran J Public Health. 2016;45(6):729-38. https://doi. org/10.3390/ijerph15020325

\section{PMid:27648415}

13. Dauletyarova MA, Semenova YM, Kaylubaeva G Manabaeva GK, Toktabayeva B, Zhelpakova MS, et al. Are Kazakhstani women satisfied with antenatal care? Implementing the WHO tool to assess the quality of antenatal services. Int J Environ Res Public Health. 2018;15(2):325. https://doi. org/10.3390/ijerph15020325

PMid:29438330

14. Gladman DD, Urowitz MB, Goldsmith CH, Fortin P, Ginzler E, Gordon $\mathrm{C}$, et al. The reliability of the systemic lupus international collaborating clinics/American college of rheumatology damage index in patients with systemic lupus erythematosus. Arthritis Rheum. 1997;40(5):809-13. https://doi.org/10.1002/ art. 1780400506

PMid:9153540

15. Lam GK, Petri M. Assessment of systemic lupus erythematosus. Clin Exp Rheumatol. 2005;23(39):S120-32.

PMid:16273796

16. Halyk Finance. National Statistics Committee of the Ministry of National Economy, Kazakhstan is on the Rise, Kazakhstanis are in Recession; 2017. Available from: https://www. inbusiness.kz/ru/news/kazahstan-na-podeme-kazahstancy-vrecessii\#gallery-2. [Last accessed on 2019 Dec 01].

17. Pascoe K, Lobosco S, Bell D, Hoskin B, Chang DJ, Pobiner B, et al. Patient-and physician-reported satisfaction with systemic lupus erythematosus treatment in US clinical practice. Clin Ther. 2017;39(9):1811-26. https://doi.org/10.1016/j. clinthera.2017.12.009

PMid:28803702

18. Ministry of National Economy of the Republic of Kazakhstan. Demographic Yearbook of Kazakhstan, Statistical Compilation.
Astana: Ministry of National Economy of the Republic of Kazakhstan; 2017. p. 357.

19. Order of the Minister of Health of the Republic of Kazakhstan. On Approval of the Rules for Setting Tariffs for Medical Services Provided Within the Guaranteed Volume of Free Medical Care and in the System of Compulsory Social Health Insurance and the Methodology for Setting Tariffs for Medical Services Provided in the Framework of Guaranteed the Volume of Free Medical Care and in the System of Compulsory Social Health Insurance. Kazakhstan: Order of the Minister of Health of the Republic of Kazakhstan; 2009. https://doi.org/10.1016/j.jval.2013.03.1262

20. Zhang L, Luan W, Geng S, Ye S, Wang X, Qian L, et al. Lack of patient education is risk factor of disease flare in patients with systemic lupus erythematosus in China. BMC Health Serv Res. 2019;19(1):378. https://doi.org/10.1186/s12913-019-4206-y PMid:31196083

21. Kulczycka L, Sysa-Jedrzejowska A, Robak E. Quality of life and satisfaction with life in SLE patients-the importance of clinical manifestations. Clin Rheumatol. 2010;29(9):991-7. https://doi. org/10.1007/s10067-010-1509-0

PMid:20532577

22. Strand V, Galateanu C, Pushparajah DS, Nikaï E, Sayers J, Wood R, et al. Limitations of current treatments for systemic lupus erythematosus: A patient and physician survey. Lupus. 2013;22(8):819-26. https://doi.org/10.1177/0961203313492577 PMid:23817511

23. Da Costa D, Clarke AE, Dobkin PL, Senecal JL, Fortin PR, Danoff DS, et al. The relationship between health status, social support and satisfaction with medical care among patients with systemic lupus erythematosus. Int J Qual Health Care. 1999;11(3):201-7. https://doi.org/10.1093/intqhc/11.3.201 PMid: 10435840

24. Batbaatar E, Dorjdagva J, Luvsannyam A, Savino MM, Amenta P. Determinants of patient satisfaction: A systematic review. Perspect Public Health. 2017;137(2):89-101. https://doi. org/10.1177/1757913916634136 PMid:27004489

25. Van Vugt RM, Derksen RH, Kater L, Bijlsma JW. Deforming arthropathy or lupus and rhupus hands in systemic lupus erythematosus. Ann Rheum Dis. 1998;57(9):540-4. https://doi. org/10.1136/ard.57.9.540

PMid:9849313

26. Grossman JM. Lupus arthritis. Best Pract Res Clin Rheumatol. 2009;23(4):495-506. https://doi.org/10.1016/j.berh.2009.04.003 PMid: 19591780

27. Woolf $A D$, Pfleger B. Burden of major musculoskeletal conditions. Bull World Health Organ. 2003;81(9):646-56. PMid:14710506

28. Tench CM, McCurdie I, White PD, D'Cruz DP. The prevalence and associations of fatigue in systemic lupus erythematosus. Rheumatology (Oxford). 2000;39(11):1249-54. https://doi. org/10.1093/rheumatology/39.11.1249

PMid:11085805

29. Gromova O, Doschanova A, Lokshin V, Tuletova A Grebennikova G, Daniyarova L, et al. Vitamin D deficiency in Kazakhstan: Cross-sectional study. J Steroid Biochem Mol Biol. 2020;199:105565. https://doi.org/10.1016/j.jsbmb.2019.105565 PMid:31812522

30. Chiewthanakul P, Sawanyawisuth K, Foocharoen C, Tiamkao S Clinical features and predictive factors in neuropsychiatric lupus. Asian Pac J Allergy Immunol. 2012;30(3):246. https://doi. org/10.12932/ap0767

PMid:22523908

31. Palagini L, Mosca M, Tani C, Gemignani A, Mauri M, Bombardieri S. Depression and systemic lupus erythematosus: 
A systematic review. Lupus. 2013;22(5):409-16. https://doi. org/10.1177/0961203313477227

PMid:23427220

32. Semenova Y, Pivina L, Manatova A, Bjørklund G, Glushkova N, Belikhina $\mathrm{T}$, et al. Mental distress in the rural Kazakhstani population exposed and non-exposed to radiation from the Semipalatinsk nuclear test site. J Environ Radioact. 2019;203:39-47. https://doi.org/10.1016/j.jenvrad.2019.02.013 PMid:30849560

33. Hanly JG, O'Keeffe AG, Su L, Urowitz MB, Romero-Diaz J, Gordon C, et al. The frequency and outcome of lupus nephritis: Results from an international inception cohort study. Rheumatology (Oxford). 2016;55(2):252-62.

PMid:26342222

34. Milchakov KS, Shilov EM, Shvetzov MY, Madyanova VV, Khalfin RA, Pivina, LM, et al. Management of chronic kidney disease in the Russian federation: A critical review of prevalence and preventive programmes. Int J Healthc Manag. 2019;12(4):3226. https://doi.org/10.1080/20479700.2018.1453970
35. Bertsias G, Gordon C, Boumpas DT. Clinical trials in systemic lupus erythematosus (SLE): Lessons from the past as we proceed to the future--the EULAR recommendations for the management of SLE and the use of end-points in clinical trials. Lupus. 2008;17(5):437-42. https://doi.org/10.1177/0961203308090031 PMid: 18490423

36. Semenova $Y$, Zhunussov $Y$, Pivina L, Abisheva A, Tinkov A, Belikhina $\mathrm{T}$, et al. Trace element biomonitoring in hair and blood of occupationally unexposed population residing in polluted areas of East Kazakhstan and Pavlodar regions. J Trace Elem Med Biol. 2019;56:31-7. https://doi.org/10.1016/j.jtemb.2019.07.006 PMid:31442951

37. George T, Elgharbawy MA, Fathi AA, Bhutta ZA, Pathan SA Jenkins $D$. Inaccuracy in electronic medical record-reported wait times to initial emergency physician evaluation. Int $\mathrm{J}$ Healthc Manag. 2020;13(1):22-7. https://doi.org/10.1080/20479700.201 7.1418277

38. Deshwal P, Bhuyan P. Cancer patient service experience and satisfaction. Int J Healthc Manag. 2018;11(2):88-95. 